\title{
Potential Thermotolerant Lactobacilli Isolated from Chicken Gastrointestinal Tract for Probiotic Use in Poultry Feeds
}

\author{
M Mizanur Rahaman ${ }^{1}$, M Nur Hossain ${ }^{1}$, Nantu Chandra Das ${ }^{2}$, Monzur Morshed Ahmed ${ }^{1}$ and M Mahfuzul Hoque ${ }^{3 *}$ \\ ${ }^{I}$ Industrial Microbiology Laboratory, Institute of Food Science and Technology (IFST), Bangladesh Council of Scientific \& Industrial Research (BCSIR), \\ Dhaka 1205, Bangladesh, ${ }^{2}$ Department of Microbiology, Jagannath University, Dhaka 1100, Bangladesh, ${ }^{3}$ Department of Microbiology, Dhaka University, \\ Dhaka 1000, Bangladesh
}

\begin{abstract}
This research was carried out to isolate and identify thermotolerant lactobacilli from broiler chicken gastrointestinal tract from Dhaka, Bangladesh. Twenty five thermotolerant Lactobacillus strains were isolated and identified as Lactobacillus species based on cultural characteristics, biochemical tests, and sugar fermentation. The probiotic are a live microbial feed supplements which positively affects the health of the host animal by improving its intestinal balance.The results showed only four among twenty five isolates were highly responded to probiotic criteria such as low pH tolerance (2.5), bile salt tolerance (2\%) and sodium chloride salt tolerance $(5 \%)$ in vitro, and were identified strains as Lactobacillus plantarum img-02, Lactobacillus plantarum img-08, Lactobacillus plantarum img-10 and Lactobacillus acidophilus img-14 according to Bergey's Manual of Systematic Bacteriology. Four isolates grow enough at $45^{\circ} \mathrm{C}$ and two isolates (Lactobacillus plantarum img-10 and Lactobacillus acidophilus img-14) heat stable at $60^{\circ} \mathrm{C}$ for $30 \mathrm{~min}$. All the strains were showed protease activity on skim milk agar. These strains were resistance to commercial antibiotic ciprofloxacin, gentamycin, imipenem and penicillin $\mathbf{G}$ but sensitive to ampicillin, doxycycline, erythromycin and tetracycline; also have antimicrobial activity against common pathogen such as ATCC of Salmonella enteritidis, Staphylococcus aureus, Listeria monocytogenes, Shigella flexneri, Bacillus cereus, Klebsiella pneumonia, Escherichia coli (environmental isolates), Aspergillus flavus and Candida albicans. This study concludes that these isolates may be used as potential candidate as probiotic poultry feed.
\end{abstract}

Key words: Thermotolerant lactobacilli, Probiotics, Poultry feeds

\section{Introduction}

Probiotic microorganisms and organic acids maintain the beneficial effect as an alternative to the use of antibiotics in feeds ${ }^{1}$. A probiotic is a "live microbial feed supplement which beneficially affects the host animal by improving its intestinal microbial balance"2-3. Antibiotics have been supplemented to animal and poultry feed to improve growth performance and efficiency; protect animals from adverse effects of pathogenic and non-pathogenic enteric microorganisms ${ }^{4}$. There are also reports that antibiotics could increase the colonization of the chicken gut by salmonellae, creating a potential public health problem ${ }^{5}$. The feeding of antibiotics also resulted in the retention of antibiotics in animal tissue, imbalances in normal intestinal flora, reduced beneficial intestinal microbial populations, and the generation of antibiotic-resistant bacteria. To overcome these problems, efforts have been directed towards the development and use of probiotics in food animals ${ }^{6}$. Probiotic supplementation of the intestinal microflora in poultry, especially with Lactobacillus species, showed beneficial effects on resistance to infectious agents such as Escherichia coli ${ }^{7}$, Salmonella spp. ${ }^{8}$. The significant roles of probiotics activities are determined in improving digestive functions, as well in immune system against infectious diseases ${ }^{9}$. The natural intestinal flora is a protective barrier against pathogens that can also affect nutrient digestion and absorption. Commercial probiotics constitute single or multiple strains of beneficial bacteria. Among the potential probiotics, lactic acid bacteria (LAB) are reported to have important effects in animals ${ }^{10}$. In vivo studies investigating health benefits of potential probiotics are time-consuming and often expensive; hence, the consequent use of in vitro tests as selection criteria to reduce the number of strains and find the most effective organism is unavoidable. Antimicrobial effects are major characteristics in the selection of $\mathrm{LAB}$ as probiotic candidates because these attributes provide competitiveness against enteric pathogens and reduce their colonization ${ }^{11}$. Recent studies have focused on improving the probiotic efficacy and represent more applicable supplements in poultry nutrition. The aim of the research work was to identify thermotolerant lactobacilli strains isolated from gastrointestinal digestive tracts of broiler chiken and study their responses to the criteria's selection probiotic in order to select strains to be used as probiotic in the poultry feed.

\section{Materials and Methods}

Sample collection: Thirty broiler chickens (Gallus gallus domesticus) were collected from Rayerbazar, Farmgate, New Market, and Azimpur in Dhaka City, Bangladesh.

*Corresponding author: Dr. Md. Mahfuzul Hoque, Professor, Department of Microbiology, University of Dhaka, Dhaka 1000, Bangladesh 
Lactobacillus species isolation: The Lactobacillus strains were isolated from jejunum, ileum, and caecum of chicken. Two $\mathrm{cm}$ portion of digestive tract was mixed with sterile saline buffer $(0.85 \%, \mathrm{pH} 7.0)$ and homogenized using a stomacher. Decimal dilution of these samples was inoculated on selective de Man, Rogosa and Sharpe (MRS) agar medium (HiMedia, India) at $45^{\circ} \mathrm{C}$ for $48 \mathrm{~h}$ under anaerobic conditions at anaerobic jar (Oxoid, UK). Then colonies with different morphology were randomly selected from the highest dilutions of each MRS agar plate and then sub cultured to acquire pure isolates.

Strain identification and preservation: Citrate utilization, indole, nitrate reduction and motility test; arginine and gelatin hydrolysis were performed. Sugar fermentation was determined in carbohydrate consumption broth (HiMedia, India) and supplemented with $1 \%$ sugar. Seventeen sugars (arabinose, fructose, galactose, glucose, lactose, maltose, mannitol, mannose, melibiose, raffinose, rhamnose, ribose, salicin, sorbitol, sucrose, trehalose and xylose) were subjected to a fermentation test under anaerobic condition; each tube was topped up with two drops of sterile liquid paraffin after inoculation. The isolates were identified using standard morphological, cultural and biochemical reactions ${ }^{12}$. Gram positive and catalase, oxidase negative isolates were stored at " $20^{\circ} \mathrm{C}$ in MRS broth supplemented with $20 \%$ (v/ v) glycerol.

Reference microorganisms: Lactobacillus acidophilus ATCC 314, Lactobacillus rhamnosus ATCC 7469 and were used as reference microorganisms and as positive control. Escherichia coli ATCC 8739, Bacillus subtilis ATCC 11774 was used as negative control.

Inhibitory substances tolerance: The probiotic characteristic was tested by using the sensitivity or resistance to low $\mathrm{pH}(2.5)$, sodium chloride salt tolerance (6.5\%) and bile salt (2\%) (Oxgall, Oxoid, UK). Acid and bile salt resistance can be considered important properties of probiotic lactic acid bacteria ${ }^{11,13}$. The physiological concentration of bile salts in the small intestine is between 0.2 and $2.0 \%{ }^{14}$. The isolated lactobacilli were subjected to primary screening for acid, sodium chloride salt and bile salt tolerance in MRS broth adjusted to $\mathrm{pH} 2.5,3,4,5$ with $1 \mathrm{~N} \mathrm{HCl}$ 1 to $8 \%$ and $0.5,1.0,1.5,2.0 \%$ with bile salt respectively. The determination of growth was performed by $1.0 \%$ bacterial suspension inoculated in MRS broth and observed after $18 \mathrm{~h}$ after anaerobic incubation at $45^{\circ} \mathrm{C}$. The experiment was performed in duplicate and the mean values were calculated.

Gastric juice tolerance: Twenty five isolated lactobacilli were subjected to primary screening to gastric juice tolerance $(0.5 \%$ Bile Salt, $0.2 \% \mathrm{NaCl}, 0.32 \%$ pepsin and $\mathrm{pH} 2.5$ ) in MRS broth; control with MRS broth medium $\mathrm{pH}$ 6.2. The determination of tolerance was performed by $1.0 \%$ bacterial culture inoculated in MRS broth and the growth was observed after $18 \mathrm{~h}$ after anaerobic incubation at $45^{\circ} \mathrm{C}$. Then absorbance was taken at $600 \mathrm{~nm}$ of 18 $\mathrm{h}$ culture.
Heat tolerance: Four Lactobacillus isolates was inoculated at $1 \%$ in MRS broth medium and incubated at different temperatures such as $15,20,25,30,37,40,45$ and $50^{\circ} \mathrm{C}$ for $18 \mathrm{~h}$ and the growth was monitored by measuring the absorbance value of broth at $600 \mathrm{~nm}$. Temperature tolerance was observed at 55, 60 and $65^{\circ} \mathrm{C}$ for 10,20 and $30 \mathrm{~min}$ in heating water bath (Clifton, England) with 2\% Lactobacillus cultures in MRS broth medium.

Proteolytic activity: The proteolytic activity was determined on skim milk agar. The strains were inoculated by $3 \mathrm{~mm}$ diameter and incubated for $24 \mathrm{~h}$ at $37^{\circ} \mathrm{C}$. The proteolysis activity is characterized by the observation of a clear zone surrounding the colonies $^{15}$.

Antimicrobial activity: Agar spot test method ${ }^{16-17}$ and agar well diffusion method ${ }^{18}$ were used to detect of inhibitory activity of Lactobacillus spp. These assays were performed in duplicate. For the agar spot test, overnight culture of Lactobacillus spp. were spotted $(3 \mathrm{~mm})$ into the surface of MRS agar (HiMedia, India) plates and incubated in anaerobic jar for $48 \mathrm{~h}$ at $45^{\circ} \mathrm{C}$ to allow colonies to develop. Approximately $5 \times 10^{7}$ colony forming unit (cfu) of test microorganisms was swabbed in the plate in which Lactobacillus spp. was grown. After incubation for $24 \mathrm{~h}$ at $45^{\circ} \mathrm{C}$, the radius of the clear inhibition zone around Lactobacillus spp. was recorded. For agar well diffusion method 4 wells in each plate of $4 \mathrm{~mm}$ in diameter were cut into tryptone soya agar (TSA, Oxoid,UK) plate by using a sterile borer and $100 \mu \mathrm{l}$ of the cell free supernatant (centrifugation at $10,000 \times \mathrm{g}$ for $5 \mathrm{~min}, 4^{\circ} \mathrm{C}$ ) of the isolates were placed into different well. The cell-free supernatant was adjusted to $\mathrm{pH} 6.2$ using $1 \mathrm{NNaOH}$ and it was used as crude bacteriocin The plates were preinoculated at room temperature for the diffusion and incubated aerobically overnight at $45^{\circ} \mathrm{C}$. The plates were examined for zones of inhibition.

Test organisms: For the detection of antimicrobial activity of Lactobacillus isolates against pathogenic microorganisms Listeria monocytogenes (2) ATCC 19112, Staphylococcus aureus ATCC 9144, Shigella flexneri (2b) ATCC 12022, Klebsiella pneumoniae ATCC 13883, Escherichia coli (environmental isolate), Vibrio parahaemolyticus ATCC 17802, Bacillus cereus ATCC 10876, Aspergillus niger, Acetobacter spp. Saccharomyces cerevisiae, Candida spp.

Antibiotic susceptibility: Antibiotic susceptibility of strains of lactobacilli was determined in vitro using the Kirby-Bauer agar disc diffusion method ${ }^{19}$. The commercial antibiotic discs used in this study were $\mathrm{AM}=$ ampicillin $(10 \mu \mathrm{g}), \mathrm{AK}=\operatorname{amikacin}(30$ $\mu \mathrm{g}), \mathrm{CIP}=$ ciprofloxacin $(5 \mu \mathrm{g}), \mathrm{DO}=$ doxycycline $(30 \mu \mathrm{g}), \mathrm{E}=$ erythromycin $(15 \mu \mathrm{g}), \mathrm{CN}=$ gentamycin $(10 \mu \mathrm{g}), \mathrm{IMP}=$ imipenem $(10 \mu \mathrm{g}), \mathrm{NA}=$ nalidixic acid, $\mathrm{N}=$ neomycin $(10 \mu \mathrm{g})$, $\mathrm{F}=$ nitrofurantoin $(300 \mu \mathrm{g}), \mathrm{TE}=$ tetracycline $(30 \mu \mathrm{g}), \mathrm{VA}=$ vancomycen (antibiotic disks were obtained from Emapol, Poland). MRS cultures were suspended at approximately $10^{8} \mathrm{cfu} /$ $\mathrm{ml}$ (McFarland standard 0.5) on Mueller-Hinton agar plates incubated for $24 \mathrm{~h}$ at $37^{\circ} \mathrm{C}$. For susceptibility tests, clear zone 
recommended for consideration of susceptible or resistance of an organism.

\section{Results and Discussion}

Lactobacillus species isolation and identification: A total of 30 samples (gut of broiler chicken) were analyzed and twenty five (25) isolates were identified as Lactobacillus species. Most of them were shiny creamy color, circular, smooth and convex; some of them were found to be irregular in MRS agar (HiMedia, India). Bacillary and cocci forms were positive to Gram reactions under a light microscope and most of them were rod or short rod chain and coccoid rods. Some Lactobacillus spp. was found to be irregular, short, even coccoid rods with round tappered ends, sometimes longer also ${ }^{20}$. Most of the isolates were found to be non-motile; oxidase, catalase, arginine hydrolysis, indole negative; nitrates are not reduced and gelatin was not liquefied. The results of selected isolates of Lactobacilli were shown in Table 1. Four isolates (img-02, img-08, img-10 and img-14) were able to grow at $37^{\circ} \mathrm{C}$ and $45^{\circ} \mathrm{C}$; isolates img- 02 and img- 10 cannot grow at $6.5 \% \mathrm{NaCl}(\mathrm{w} / \mathrm{v})$ but rest two isolates grow at $6.5 \%$ $\mathrm{NaCl}$. Kandler and Weiss ${ }^{21}$ have classified Lactobacillus isolates according to their morphology, physiology and molecular characteristics. These isolates were also able to ferment sugars at different percentages which were much significant for identification of the species. Among seventeen different sugars; fructose, glucose, lactose, maltose and sucrose was fermented by those 4 isolates. Galactose, melibiose, ribose and salicin were utilized by $75 \%$ of the isolates; $50 \%$ of the isolated isolates were able to ferment trehalose and mannitol sugars; arabinose, raffinose, rhamnose and xylose was not fermented by any one of the 4 isolates.

Inhibitory substances tolerance: Probiotic potential of lactobacilli had ability to resist bile salts and acidic $\mathrm{pH}^{22}$. Tolerance to bile salts is a prerequisite for colonization and metabolic activity of bacteria in the small intestine of the host $\mathrm{t}^{23}$. The effect of $\mathrm{pH}$ $(2.5,3,4$ and 5$)$ and bile salts $(0.5,1.0,1.5$ and $2.0 \%)$ and $\mathrm{NaCl}$ ( 1 to $6.5 \%$ ) of 25 isolates was studied. It was found that most isolates might grow at above criteria except $\mathrm{pH}$ 2.5-3.0 and bile concentration $1.5-2 \%$. But most of them were able to survive that low $\mathrm{pH}$ and bile salt. Jacobsen et al. ${ }^{24}$ suggested that the $\mathrm{pH}$ of 2.5 seemed to be damaging to the bacteria. The isolates from our experiment showed stronger bile tolerance than those reported by other investigators ${ }^{25}$. In this study, four probiotic isolates (img-

Table 1 Phenotypic and biochemical characteristics of selected lactobacilli

\begin{tabular}{|c|c|c|c|c|c|}
\hline Test parameter & img-02 & img-08 & img-10 & imbg-14 & \\
\hline Growth at $15^{\circ} \mathrm{C}$ & - & - & - & - & \\
\hline Growth at $37^{\circ} \mathrm{C}$ & + & + & + & + & \\
\hline Growth at $45^{\circ} \mathrm{C}$ & + & + & + & + & \\
\hline Growth at $6.5 \% \mathrm{NaCl}$ & - & + & - & + & \\
\hline Growth at $8 \% \mathrm{NaCl}$ & - & - & - & - & \\
\hline Hydrolysis of arginine, gelatine & - & - & - & - & \\
\hline Citrate utilization & - & - & - & - & \\
\hline Indole, Motility, Nitrate reduction & - & - & - & - & \\
\hline Survival at $60^{\circ} \mathrm{C}$ for $30 \mathrm{~min}$ & - & - & + & + & \\
\hline Arabinose & - & - & - & - & \\
\hline Cellobiose & + & - & + & + & \\
\hline Fructose & + & + & + & + & \\
\hline Galactose & + & + & + & + & \\
\hline Glucose(acid) & + & + & + & + & \\
\hline Glucose(gas) & - & - & - & - & \\
\hline Lactose(acid) & + & + & + & + & \\
\hline Maltose & + & - & - & - & \\
\hline Mannitol & & + & - & - & + \\
\hline Mannose & + & - & + & + & \\
\hline Melibiose & + & + & - & + & \\
\hline Raffinose & - & - & - & - & \\
\hline Rhamnose & - & - & - & - & \\
\hline Ribose & + & - & - & + & \\
\hline Salicin & + & + & + & + & \\
\hline Sorbitol & - & - & - & - & \\
\hline Sucrose & + & + & + & + & \\
\hline Trehalose & + & + & + & + & \\
\hline Xylose & - & - & - & - & \\
\hline Esculin hydrolysis & + & + & + & + & \\
\hline Protease activity (milimiter) & 35 & 25 & 18 & 25 & \\
\hline
\end{tabular}


02, img-08, img-10 and img-14) showed acid tolerance at $\mathrm{pH}$ 2.5 sodium chloride salt tolerances at $5 \%(\mathrm{w} / \mathrm{v})$ and bile salt tolerance at $2 \%(\mathrm{w} / \mathrm{v})$. On the basis of low $\mathrm{pH}$ tolerance and high bile salt tolerance test twelve (12) presumptive Lactobacillus spp. were selected for gastric juice tolerance test.

Gastric juice tolerance: Among 12 only four Lactobacillus isolates (img-02, img-08, img-10 and img-14) had excellent growth with the gastric juice composition $(0.5 \%$ bile salt, $0.2 \%$ $\mathrm{NaCl}, 0.32 \%$ pepsin) in MRS broth up to $\mathrm{pH} 4$ and significantly survive at $\mathrm{pH} 2.5$. These were excellent probiotics. The survival of L. plantarum, L. acidophilus L. rhamnosus strains in simulated gastric juice, $\mathrm{pH} 2.0$, for $90 \mathrm{~min}^{26}$.

Heat tolerance: Four Lactobacillus isolates was inoculated at $1 \%$ in MRS broth medium and incubated at different temperatures such as $15,20,25,30,37,40,45$ and $50^{\circ} \mathrm{C}$ for $18 \mathrm{hrs}$ and the growth was monitored by measuring the absorbance value of broth at $600 \mathrm{~nm}$. The experiment was performed in triplicate and the mean values were calculated (Figure: 1). Temperature tolerance was observed at 55,60 and $65^{\circ} \mathrm{C}$ for 10,20 and $30 \mathrm{~min}$ in heating water bath (Clifton, England) with 2\% Lactobacillus cultures in MRS broth medium. Survival study in high temperature was measured by plate count method. Four isolates had shown stability at $55^{\circ} \mathrm{C}$ but not at $65^{\circ} \mathrm{C}$; only Lactobacillus plantarum img- 10 and $L$. acidophilus img- 14 were stable at $60^{\circ} \mathrm{C}$ for $30 \mathrm{~min}$.

Proteolytic activity: Selected four isolates were proteolytic lactobacilli. The proteolyse activity of these bacteria is benefit for host, by the liberation of the amino acids from feed or endogenous proteins. Isolated L. acidophilus from chicken gut was proteolytic probiotic microorganisms ${ }^{27}$.

Antimicrobial activity: Lactic acid bacteria pose a strong antagonistic activity against foodborne pathogenic microorganisms as a result of the production of organic acids, hydrogen peroxide, inhibitory enzymes and bacteriocins ${ }^{28-29}$. Antimicrobial activity of probiotic microorganisms may contribute to an improvement in the quality of fermented foods. This may result from control of spoilage and pathogenic bacteria, extension of shelf life, and improvement of sensory quality ${ }^{30-31}$. The results (Table 2) showed that all of the four strains were able to inhibit the growth of eight pathogenic microorganisms. Two strains (L. plantarum img-10 and L. acidophilus imy-14) among 4 were excellent to inhibit the most pathogenic microorganisms (Table 3). This indicates that inhibitory factors secreted into environment. This result is in concordance with the results of Kos et al..$^{32}$ who was demonstrated anti-Salmonella activity of probiotic strains $L$. acidophilus M92 and L. plantarum L4; $L$. acidophilus M92 was also shown to have anti-listerial activity.

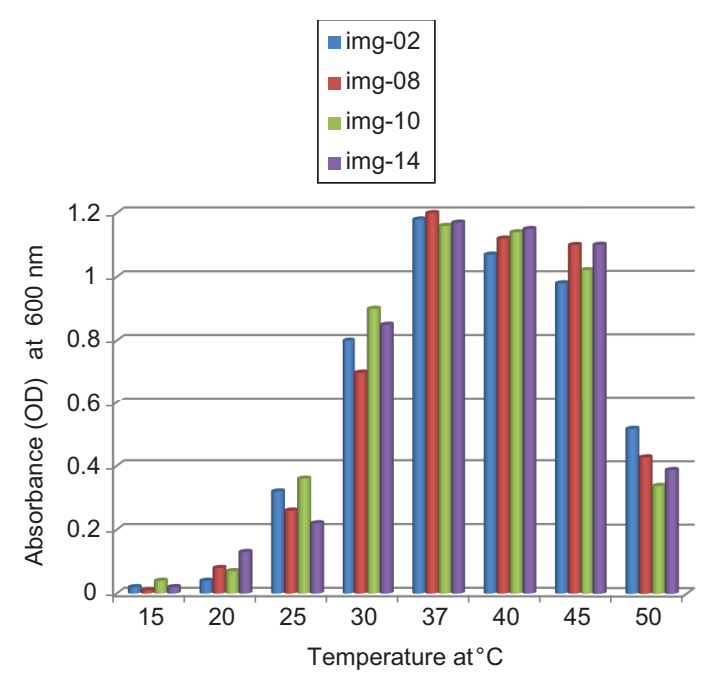

Figure 1. Growth absorbance (OD) at $600 \mathrm{~nm}$ after $18 \mathrm{~h}$ of different temperature.

Table 2. Antimicrobial activity

\begin{tabular}{lccccc}
\hline Name of the test microorganism & \multicolumn{4}{c}{ Diameter of zone of inhibition in mm } \\
\cline { 2 - 6 } & *Control & img-02 & img-08 & img-10 & imy-14 \\
\hline Salmonella Enteritidis ATCC 13076 & 10 & 15 & 15 & 10 & 15 \\
Staphylococcus aureus ATCC 9144 & 10 & 5 & 5 & 10 & 10 \\
Escherichia coli (environmental isolate) & 5 & 10 & 15 & 5 & 5 \\
Klebsiella pneumoniae ATCC 13883 & 5 & 10 & 10 & 5 & 5 \\
Shigella flexneri (2b) ATCC 12022 & 8 & 5 & 10 & 15 & 15 \\
Listeria monocytogenes (2) ATCC 19112 & 5 & 5 & 10 & 5 & 5 \\
Vibrio parahaemolyticus ATCC 17802 & 5 & 10 & 10 & 5 & 5 \\
Bacillus cereus ATCC 10876 & 5 & 20 & 10 & 10 & 10 \\
Aspergillus flavus & 0 & 7 & 9 & 10 & 14 \\
Candida albicans & 0 & 30 & 25 & 35 & 20 \\
Saccharomyces cereviciae & 0 & 0 & 4 & 4 & 6 \\
\hline
\end{tabular}

${ }^{*}$ Control $=$ Lactobacillus rhamnosus ATCC 7469, $0=$ Not tested. 
Table 3. Antibiotic susceptibility

\begin{tabular}{lccccccccccccc}
\hline Species & $\mathrm{AM}$ & $\mathrm{AK}$ & $\mathrm{CIP}$ & $\mathrm{DO}$ & $\mathrm{E}$ & $\mathrm{CN}$ & $\mathrm{IMP}$ & $\mathrm{NA}$ & $\mathrm{N}$ & $\mathrm{F}$ & $\mathrm{TE}$ & VA & $\mathrm{P}$ \\
\hline *Control & $\mathrm{O}$ & 0 & 0 & 0 & 0 & $\mathrm{R}$ & $\mathrm{R}$ & $\mathrm{R}$ & 0 & $\mathrm{R}$ & $\mathrm{S}$ & $\mathrm{S}$ & $\mathrm{R}$ \\
img-2 & $\mathrm{S}$ & $\mathrm{R}$ & $\mathrm{R}$ & $\mathrm{S}$ & $\mathrm{S}$ & $\mathrm{R}$ & $\mathrm{R}$ & $\mathrm{R}$ & $\mathrm{R}$ & $\mathrm{I}$ & $\mathrm{S}$ & $\mathrm{R}$ & $\mathrm{R}$ \\
img-8 & $\mathrm{S}$ & $\mathrm{I}$ & $\mathrm{R}$ & $\mathrm{S}$ & $\mathrm{S}$ & $\mathrm{R}$ & $\mathrm{R}$ & $\mathrm{R}$ & $\mathrm{R}$ & $\mathrm{S}$ & $\mathrm{S}$ & $\mathrm{R}$ & $\mathrm{R}$ \\
img-10 & $\mathrm{S}$ & $\mathrm{I}$ & $\mathrm{R}$ & $\mathrm{S}$ & $\mathrm{S}$ & $\mathrm{R}$ & $\mathrm{R}$ & $\mathrm{R}$ & $\mathrm{R}$ & $\mathrm{S}$ & $\mathrm{S}$ & $\mathrm{R}$ & $\mathrm{R}$ \\
img-14 & $\mathrm{S}$ & $\mathrm{I}$ & $\mathrm{R}$ & $\mathrm{S}$ & $\mathrm{S}$ & $\mathrm{R}$ & $\mathrm{R}$ & $\mathrm{S}$ & $\mathrm{R}$ & $\mathrm{S}$ & $\mathrm{S}$ & $\mathrm{S}$ & $\mathrm{R}$ \\
\hline
\end{tabular}

$*$ Cont. $=$ Lactobacillus rhamnosus ATCC 7469, $0=$ Not tested.

The study of Tambekar and Bhutada ${ }^{33}$ showed that L. plantarum had strongest antagonistic potential against Salmonella typhi and Klebsiella pneumoniae. Obadina et al. ${ }^{34}$ also reported that $L$. plantarum, had a broad antimicrobial inhibitory spectrum, against Salmonella typhi, E. coli, S. aureus and B. cereus.

Antibiotic susceptibility: The safety of probiotic bacteria must be carefully assessed, with particular attention to transferable antibiotic resistance ${ }^{35}$. Antibiotic resistance pattern should be tested for each particular probiotic $\operatorname{strain}^{36}$. Four isolates were resistant to ciprofloxacin, gentamycin, imipenem and penicillin $\mathrm{G}$ but sensitive to ampicillin, doxycycline, erythromycin and tetracycline. Isolates img-14 was also sensitive to nalidixic acid and vacomycin (Table 3 ). This result was similar to the report of Danielsen and Wind ${ }^{37}$. They found lactobacilli have a high natural resistance to ciprofloxacin, kanamycin, gentamicin, nitrofurantoin, and vancomycin. The resistance of the probiotic strains to antibiotics used for both preventive and therapeutic purposes in controlling intestinal infections and faster recovery of the patients due to rapid establishment of desirable microbial flora $^{38}$. Ahmed ${ }^{39}$ suggested uses probiotic as alternatives to antibiotics due to rising antibiotic resistant bacteria. Resistance to ampicillin, ciprofloxacin, and vancomycin are commonly found in the genus Lactobacillus. Future experiments should investigate whether this resistance is carried by a resistance plasmid and can be transmitted to other bacteria.

\section{Conclusion}

This may be first research article that the isolation and characterization of strains of lactobacilli isolated from broiler chicken in Bangladesh. The present study revealed that isolated strains Lactobacillus plantarum img-02, Lactobacillus plantarum img-08, Lactobacillus plantarum img-14 \& Lactobacillus acodophilus img-14 were acid tolerance at $\mathrm{pH} 2.5$, sodium chloride tolerance at $5 \%$, bile tolerance at $2 \%$, antibacterial activity against enteric pathogens and able to produce the antimicrobial substances like bacteriocin which suggest their possible use in the poultry industry. These Lactobacillus isolates may be used as probiotic poultry feed to increase the natural flora of poultry gut and inhibit or reduction the pathogenic microbial contamination. These products provide restoration and maintenance of normal microbial flora of intestine, inhibit or reduction the pathogenic microbial contamination and prevention of side effect of antibiotics. Four strains are protease positive. The proteolytic activity of these bacteria is benefit for host chicken by the liberation of the amino acids from feed or endogenous proteins.

\section{References}

1. Guillot JF. 1998. Les probiotiques en alimentation animale. Cahier Agric. 7: 49-59.

2. Salminen S, von Wright A, Morelli L, Marteau P, Brassart D, de Vos WM, Fonden R, Saxelin M, Collins K, Mogensen G, Birkeland SE and Mattila-Sandholm T. 1998. Demonstration of safety of probiotics - A review, Int J Food Microbiol. 44: 93-106.

3. Reid G, Jass J, Sebulsky MT and McCormick JK. 2003. Potential uses of probiotics in clinical practice, Clinl Microbiol Rev. 16(4): 658-672.

4. Ferket PR, Parks CW and Grimes JL. 2002. Benefits of dietary antibiotic and mannanoligosaccharide supplementation for poultry. In Multi-State Poultry Meeting. May 14-16, Atlanta, GA, USA.

5. Fuller R. 1989. Probiotics in man and animals. J Appl Bacteriol. 66: 365-378.

6. Reid G, and Friendship R. 2002. Alternatives to antibiotic use: Probiotics for the gut. Anim Biotechnol. 13: 92-97.

7. Jin LZ, Ho YM, Abdullah N and Jalaldin S. 1998. Acid and bile tolerance of Lactobacillus isolated from chicken. Lett Appl Microbiol. 27: 183185 .

8. Pascual M, Hugas M, Badiola JI, Monfort JM and Garriga M. 1999. Lactobacillus salivarius CTC2197 prevents Salmonella enteritidis colonization in chickens. Appl Environ Microbiol. 65: 4981- 4986.

9. Pineiro M and Stanton C. 2007. Probiotic bacteria: Legislative frame work requirements to evidence basis. J Nutr. 137: 850-853.

10. Carr FJ, Chill D and Maida N. 2002. The lactic acid bacteria: A literature survey. Critical Rev Microbiol. 28(4): 281-370.

11. Ouwehand AC, Salminen S and Isolauri E. 2002. Probiotics: An overview of beneficial effects. Antonie Van Leeuwenhoek. 2: 279-89

12. Howells BW. 1992. Functions of Fermented Milk Challenges for the Health Science, pp 119-128. Elsevier Science Publishers Ltd., New York.

13. Miroslava M, Klingberg TD, Laukova A and Bjorn BB. 2009. The effect of $\mathrm{pH}$, bile and calcium on the adhesion ability of probiotic enterococci of animal origin to the porcine jejunal epithelial cell line IPEC-J2. Anaerobe. 21: 1-5.

14. Gunn JS. 2000. Mechanisms of bacterial resistance and response to bile. Microbes Infect. 2: 907-913.

15. Moulay M, Aggad H, Benmechernene Z, Guessas B, Henni DE and Kihal. 2006. Cultivable lactic acid bacteria isolated from Algerian raw goat's milk and their proteolytic activity. World J Dairy Food Sci. 1(1): 12-18.

16. Kilic AO, Pavlova SI, Ma W and Tao L. 1996. Analysis of Lactobacillus phages and bacteriocins in American dairy products and characterization of phages isolated from yogurt. Appl Environ Microbiol. 62: 2111-2116. 
17. Nowroozi1 J, Mirzaii1 M and Norouzi M. 2004. Study of Lactobacillus as probiotic bacteria. Iranian J Publ Health. 33(2): 1-7.

18. Toba T, Samant SK and Itoh T. 1991. Assay system for detecting bacteriocin in microdilution wells. Lett Appl Microbiol. 13: 102-104.

19. Bauer AW, Kirby WM, Sheris JC and Turck M. 1966. Antibiotic susceptibility testing by a standardized single disc method. Am J Clin Path. 45: 493-496.

20. Kandler O, Schillinger U and Weiss N. 1983. Lactobacillus halotolerans sp.nov., nom.rev. and Lactobacillus minor sp.nov., nom.rev. Systematic Appl Microbiol. 4: 280-285.

21. Kandler O and Weiss N. 1986. Genus Lactobacillus beijerinck. 1901. In Bergey's Manual of systematic Bacteriology. 2: 1209-1234.

22. Lee YK and Salminen S. 1995. The coming of age of probiotics. Trends Food Sci Technol. 6: 241-245.

23. Havenaar R, Ten Brink B and Huis in't Veld JHJ. 1992. Selection of strains for probiotic use. In Probiotics: The Scientific Basis (Fuller R ed), pp 209-224. Chapman and Hall, London.

24. Jacobsen CN, Nielsen VR, Hayford AE, Moller PL, Michaelsen, KF, Paerregaard A, Standstrom B, Tvede M and Jacobsen M. 1999. Screening of probiotic activities of forty-seven strains of Lactobacillus spp. by in vitro techniques and evaluation of the colonization ability of five selected strains in human. Appl Environ Microbiol. 65: 4949-4956.

25. Papamanoli E, Tzanetakis N, Litopoulou-Tzanetaki E and Kotzekidou P. 2003. Characterization of lactic acid bacteria isolated from a Greek dryfermented sausage in respect of their technological and probiotic properties. Meat Sci. 65: 859-867.

26. Corcoran BM, Stanton C, Fitzgerald GF and Ross RP. 2005. Survival of probiotic Lactobacilli in acidic environments is enhanced in the presence of metabolizable sugars. Appl Environ Microbiol. 71(6): 3060-3067.

27. Behira B, Moulay M and Kihal M. 2009. Probiotic potential of thermotolerants lactobacilli isolated from chicken gastrointestinal digestive and their use as poultry feed. World Appl Sci J. 7(8): 951-957.

28. Piard JC and Desmazeaud M. 1991. Inhibiting factors produced by lactic acid bacteria: 1. Oxygen metabolites and catabolism en-products. Lait. 71: $525-541$.
29. Juven BJ, Schved F and Lindner P. 1992. Antagonistic compounds produced by a chicken intestinal strain of Lactobacillus acidophilus. $J$ Food Protect. 55: 157-161.

30. Wei H, Wolf G and Hammes WP. 2006. Indigenous microorganisms from iceberg lettuce with adherence and antagonistic potential for use as protective culture, Innovative Food Science Emerging Technologies. 7: 294-301.

31. Siripatrawan U and Harte BR. 2007. Solid phase microextraction/gas chromatography/mass spectrometry integrated with chemometrics for detection of Salmonella typhimurium contamination in a packaged fresh vegetable. Analytica Chimica Acta. 581: 63-70.

32. Kos B, Suskovic J, Beganovic J, Gjuracic K, Frece J, Iannaccone C and Canganella F. 2008. Characterization of the three selected probiotic strains for the application in food industry, World J Microbiol Biotechnol. 24(5): 699-707.

33. Tambekar DH and Bhutada SA. 2010. An evaluation of probiotic potential of Lactobacillus sp. from milk of domestic animals and commercial available probiotic preparations in prevention of enteric bacterial infections. Recent Res Sci Technol. 2(10): 82-88.

34. Obadina AO, Oyewole OB, Sanni LO and Tomlins KI. 2006. Biopreservative activities of Lactobacillus plantarum strains in fermenting casssava 'fufu', African J Biotechnol. 5(8): 620-623.

35. Mathur S and Singh R. 2005. Antibiotic resistance in food lactic acid bacteria “ A review. Int J Food Microbiol. 105(3): 281-295.

36. Charteris WP, Kelly PM, Morelli L and Collins JK. 1998. Development and application of an in vitro methodology to determinate the transit tolerance of potentially probiotic Lactobacillus and Bifidobacterium species in the upper human gastrointestinal tract. J Appl Microbiol. 84: 759-768.

37. Danielsen M and Wind A. 2003. Susceptibility of Lactobacillus spp. to antimicrobial agents, Int J Food Microbiol. 82: 1-11.

38. EI-Naggar MYM. 2004. Comparative study of probiotic cultures to control the growth of E. coli O157:H7 and Salmonella typhimurium. Biotechnology. 3:173-180.

39. Ahmed FE. 2003. Genetically modified probiotics in foods. Trends Biotechnol. 21: 491-497. 